\title{
Preparation, Solid-State Characterization, Phase Solubility and Dissolution Studies of Azithromycin/Hydroxypropyl- $\beta$ - Cyclodextrin Host-Guest System
}

\author{
Mihir Raval, Hina Bagada* \\ Department of Pharmaceutical Sciences, Saurashtra University, Rajkot, Gujarat, INDIA.
}

\begin{abstract}
Objectives: Azithromycin has poor aqueous solubility and its dissolution is the rate-limiting step. Therefore the objective of this work to increase the solubility and dissolution of azithromycin. Hence aim of the study was to develop, characterize and evaluate dissolution properties of inclusion complexes of Azithromycin with hydroxypropyl- $\beta$-cyclodextrin (HP- $\beta-C D$ ). Methods: Phase solubility was performed by Higuchi and Connors's method for determination of stoichiometry of AZM/ $\beta-C D$ and AZM/ HP- $\beta-C D$ inclusion complex. It again confirmed by Jobs plot. Inclusion complex of Azithromycin with hydroxypropyl- $\beta$-cyclodextrin (HP- $\beta-C D$ ) was prepared by kneading method and solvent evaporation method in molar ratio of 1:1. The inclusion complex in solid state was characterized by FT-IR, DSC, HNMR, SEM. Results: AL type was found in the phase solubility diagram which indicated the development of the inclusion complex in 1:1 stoichiometry with HP- $\beta-C D$. The stability constant decrease with increasing temperature. All thermodynamic parameters for the inclusion complex were calculated from Van't Hoff plots. The highest enhancement in dissolution and solubility were observed in the inclusion complex developed with HPß-CD using the kneading method. FT-IR spectra exhibited that the hydroxyl group of
\end{abstract}

azithromycin was participate in inclusion process. DSC study supported amorphization of drug molecule and entrapment of drug in the HP- $\beta-C D$ cavity. It further confirmed with nuclear magnetic resonance and scanning electron microscopy studies. Conclusion: The solubility was significantly improved by the inclusion complex with HP- $\beta$-CD (9 fold). The dissolution of azithromycin was improved with inclusion phenomena using kneading method. The result of studies showed the inclusion of Azithromycin molecule inside HP- $\beta$-CD cavities.

Key words: Azithromycin, Hydroxypropyl- $\beta$-cyclodextrin, Inclusion complex, Kneading method

Correspondence

Hina Bagada,

Department of Pharmaceutical Sciences, Saurashtra University, Rajkot-360005, Gujarat, INDIA.

Phone no: +91-9979664719

Email: bagadahina@gmail.com

DOI: 10.5330/ijpi.2019.4.33

\section{INTRODUCTION}

Azithromycin (AZM) is one of the best antibiotic related to semisynthetic macrolide class. Azithromycin has mainly prevented the growth of bacteria such as Mycobacterium avium, Streptococcus, Staphylococcus aureus, Pneumonia, Mycoplasma pneumonia, Haemophilus influenza etc. ${ }^{1}$ Azithromycin was useful for various disorders like pulmonary disease, pneumonia, respiratory tract disorders, bronchiectasis and nontuberculous mycobacterial pulmonary diseases. ${ }^{2,3}$ According to BCS classification, Azithromycin (AZM) can be classified as a class II drug. It means that it is a poorly water-soluble drug. ${ }^{4,5}$

The Supramolecular chemistry is one of an important part of chemical analysis. These studies explained about intermolecular interactions. ${ }^{67}$ One type of intermolecular interaction is due to the host-guest system. ${ }^{8}$ Cyclodextrin is one of the best choices to form an inclusion complex with the most lipophilic part of the molecule into the cavity. ${ }^{9,10}$ The inclusion complexes improve water solubility as well as stability. ${ }^{11,12}$ Hence, this inclusion complex has also modified the physical as well as biological properties of guest drug molecules. ${ }^{13}$ The interaction forces in the inclusion complex are the liberation of water molecules from the hydrophilic part, van der Waals interactions, electrostatic interactions, hydrogen bonding and hydrophobic interactions. Hydroxypropyl-beta-cyclodextrin (HP $\beta$-CD) and Beta-cyclodextrin were selected for this study to improve the dissolution rate of Azithromycin in phosphate buffer $\mathrm{pH}$ 6.8. Hence, the objective of this research work was to develop an inclusion complex of AZM with cyclodextrin in order to improve its dissolution.

\section{MATERIALS AND METHODS}

\section{Material}

HP- $\beta$-CD and $\beta$-CD were obtained as gift sample from Roquette Riddhi Siddhi Pvt. Ltd. Mumbai India. Azithromycin dihydrate was also received as a gift sample from Alembic Pharmaceutical, Vadodara, India. All solvent and other chemicals used were A.R. grade. Double distilled water (fresh) was used during the work.

\section{Phase solubility}

Higuchi and Connors's method was used for determination of phase-solubility studies in triplicate. ${ }^{14}$ The phase solubility studies were performed with both cyclodextrin $\beta$-CD and $\mathrm{HP} \beta$-CD to evaluate the solubility. 25 $\mathrm{ml}$ of an aqueous solution of $\beta-\mathrm{CD}$ and $\mathrm{HP} \beta-\mathrm{CD}$ were prepared in screwcapped vials with increasing molar concentrations $(0,3,6,9,12$ and $15 \mathrm{mM})$ at $25^{\circ} \mathrm{C}$. Then AZM, in constant amounts, was added to above solutions and stirred using rotary shaker (Remi, India) for $48 \mathrm{hr}$. For determination of Gibbs free energy of transfer $\left(\Delta \mathrm{G}^{\circ}\right), \mathrm{HP} \beta-\mathrm{CD}$ molar concentration with AZM was stirred on a rotary shaker for $48 \mathrm{~h}$ at 25 , $27,33,43^{\circ} \mathrm{C}$ on $300 \mathrm{rpm} .{ }^{15}$ The stirring time was decided on preliminary work to achieve equilibrium. After it, the mixture solution was filtered, diluted suitably and analyzed its AZM content at 510nm (UV/Visible spectrophotometer, Shimadzu). The apparent stability constant (K1:1) for both $\mathrm{AZM} / \beta-\mathrm{CD}$ and $\mathrm{AZM} / \mathrm{HP} \beta-\mathrm{CD}$ was calculated from the linear regression of the curve respectively. 


$$
\mathrm{Kc}=\text { slope / So } \mathrm{x} \text { (1-slope) }
$$

Where Slope is found from the linear curve and so is the aqueous solubility of $\mathrm{AZM}$ at $\mathrm{pH} 6.8$ in the absence of $\mathrm{HP} \beta-\mathrm{CD}$.

\section{Job's plot (continuous variation Method)}

The stoichiometry of AZM/HP $\beta$-CD for inclusion complex was further confirmed by continuous variation method. ${ }^{16}$ The summation of the concentration of both content $[\mathrm{AZM}]$ and $[\mathrm{HP} \beta-\mathrm{CD}]$ was kept constant about $10 \times 10^{4} \mathrm{M}$, whereas the molar proportion of AZM with $\mathrm{HP} \beta-\mathrm{CD}$ was varied from 0.0 to $1.0 .(\mathrm{R}=[\mathrm{AZM}] /[\mathrm{AZM}]+[\mathrm{HP} \beta-\mathrm{CD}])$. After stirring process $(48 \mathrm{~h}$ ), the UV absorbance was noted at $510 \mathrm{~nm}$ for all solutions against blank and the difference in the absorbance between in the presence of $\mathrm{HP} \beta-\mathrm{CD}(\mathrm{A})$ and absence of $\mathrm{HP} \beta-\mathrm{CD}\left(\mathrm{A}_{0}\right)$ were also noted $\left(\Delta \mathrm{A}=\mathrm{A}-\mathrm{A}_{0}\right)$. The graph was plotted $\Delta \mathrm{A}$ vs the molar proportion $\mathrm{R}$. The maximum value in the graph for complex should indicate preferable stoichiometric ratio for the inclusion of $\mathrm{AZM} / \mathrm{HP} \beta-\mathrm{CD}$.

\section{Preparation of inclusion complex}

AZM and HP- $\beta$-CD were sieved separately through 80 \# prior to their use. Inclusion complexes of AZM/HP $\beta$-CD were developed as below in the $1: 1(0.785 \mathrm{gm}$ of AZM and $1.375 \mathrm{gm}$ of HP $\beta-C D)$ molar ratio.

\section{Physical mixture}

Physical mixture of HP $\beta$-CD and AZM was simply prepared by mixing powders in 1:1 molar ratios. The physical mixture was gently mixed until a homogeneous powder and sieved using 80\#

\section{Kneading method}

The kneading method is based on trituration process. ${ }^{17}$ It was used for the development of the inclusion complex of AZM/HP $\beta-C D$ in 1:1 molar ratios. $\mathrm{HP} \beta-\mathrm{CD}$ was first triturated in a mortar with a small amount of water to get a homogeneous paste. Accuaratly weighted AZM was added slowly in above paste during trituration with a small amount of 0.1 $\mathrm{N} \mathrm{HCl}$ was required for the solubilization of AZM. The mixtures were then triturated for $1 \mathrm{hr}$. During this trituration, a small amount of water was added to obtain the desired consistency. These prepared pastes were dried at $40-50^{\circ} \mathrm{C}$ for $24 \mathrm{hr}$ in an oven. The dried inclusion complexes were then sieved using $80 \#$

\section{Solvent evaporation}

Another inclusion complex of AZM/HP- $\beta$-CD was prepared by the solvent evaporation method in 1:1 molar ratios. ${ }^{18}$ The required amount of $\mathrm{HP} \beta-\mathrm{CD}$ was added in a beaker containing small amount of ethanol and stirrered slowly until HP $\beta$-CD dissolved. AZM was then added and agitated until a clear solution was obtained. This beaker was placed in a fume hood to allow the solvent to gently evaporate at $25 \pm 0.5^{\circ} \mathrm{C}$ for $24 \mathrm{hr}$. The resulting inclusion complex powder was dried at $40-50^{\circ} \mathrm{C}$ for $24 \mathrm{hr}$ in an oven. The dried inclusion complexes were then sieved using $80 \#$

\section{Determination of drug content in inclusion complexes}

The amount of AZM in inclusion complexes and physical mixtures were determined by dissolving a required amount of the samples in $0.1 \mathrm{~N} \mathrm{HCl}$ using UV spectrophotometer at $510 \mathrm{~nm} .{ }^{19}$

\section{Solubility study}

The solubility of AZM in inclusion complexes was determined using mechanical shaker in phosphate buffer pH $6.8(n=3)$. An excess amount of the inclusion complexes were shaken in flasks with phosphate buffer $\mathrm{pH}$ 6.8 at $25 \pm 0.5^{\circ} \mathrm{C}$ for $24 \mathrm{hr}$. The solutions were then filtered and analyzed by UV/Visible spectrophotometer at $510 \mathrm{~nm} .{ }^{19}$

\section{Dissolution studies}

The dissolution studies of AZM in pure, its physical mixture and AZM/ $\mathrm{HP} \beta-\mathrm{CD}$ inclusion complexes were conducted in triplicate to determine drug release profile. It was carried out on USP type II dissolution apparatus having $900 \mathrm{ml}$ phosphate buffer ( $\mathrm{pH}$ 6.8) as a dissolution medium at $37^{\circ} \mathrm{C} \pm 1^{\circ} \mathrm{C}$ at $50 \mathrm{rpm}$ for $120 \mathrm{~min}$. At defined time intervals, 5 $\mathrm{ml}$ aliquots were withdrawn and then filtered. They were suitably diluted and analysed for AZM content using UV spectrophotometer at $510 \mathrm{~nm}$. Preliminary study revealed no change in the $\lambda_{\max }$ of AZM in the presence of $\mathrm{HP} \beta$-CD. Equal volumes of pre-warmed phosphate buffer $\mathrm{pH} 6.8$ were added into the medium to maintain initial volume during the dissolution study. The cumulative drug release was calculated. ${ }^{20}$

\section{Solid state characterization of inclusion complex}

\section{Fourier transform infrared spectroscopic analysis}

AZM/HP $\beta-C D$ inclusion complex and pure substances were evaluated in duplicate by an FT-IR (Nicolet iS10, Thermo Fisher Scientific Inc., USA) in the range of $400-4000 \mathrm{~cm}^{-1}$ for every sample. The FT-IR spectra of the inclusion complexes were compared with their pure AZM and $\mathrm{HP} \beta-\mathrm{CD}$.

\section{Differential scanning calorimetry analysis}

DSC curve of pure AZM, HP $\beta-C D, A Z M / H P \beta-C D$ inclusion complex were measured in duplicate with a DSC-60 (Shimadzu corporation Japan system). The sample was $2 \mathrm{mg}$ weighed accurately in a DSC aluminium pan and were crimped, followed by scanning rate $10^{\circ} \mathrm{C} / \mathrm{min}$ under an inert atmosphere of nitrogen from $50-300^{\circ} \mathrm{C}$. Empty aluminum pan was used as a reference.

\section{${ }^{1} H$ NMR analysis}

Proton (1H) NMR spectra for pure AZM, HP $\beta-C D, A Z M / H P \beta-C D$ inclusion complex were obtained using a NMR spectrometer (Bruker Avance 600) with deuterated dimethyl sulfoxide (d-DMSO) as the solvents. Chemical shifts $(\delta)$ were denoted as ppm (parts per million) and referenced to DMSO signal.

\section{Scanning electron microscopy studies}

The surface morphological features of the samples were examined under SEM (ESEM EDAX XL 30 Philips XL, Netherlands). The samples were previously coated with Au to make them conductors (Edwars Auto 306).

\section{Stability study}

The optimized inclusion complex was subjected to three-month stability study as per ICH guidelines. The final inclusion complex (kneding method) and pure drug were packed with aluminium foils and placed in wide closed tightly bottles. The samples were stored at $40^{\circ} \mathrm{C} / 75 \% \mathrm{RH}$ for 3 months and analysed in triplicate. ${ }^{21,22}$

\section{RESULTS}

\section{Phase solubility}

The first host-guest stoichiometry was determined for AZM/ $\beta-C D$. The phase solubility graph for AZM with $\beta-C D 25^{\circ} \mathrm{C}$ was compared with Higuchi and Connors standard graph. Its result indicated AN-type phase-solubility shown in Figure 1. It was concluded from the obtained phase solubility diagram in case of $\beta$-CD that it can be difficult to interpret. Another reason, AZM has higher molecular weight about $785.026 \mathrm{~g} /$ mol. The high molecular weighted AZM has difficult to accommodate into smaller cavity size of $\beta$-CD. The $\beta$-CD was comparatively smaller for AZM guest molecule.

Second host-guest stoichiometry was determined for AZM/HP $\beta$-CD. The phase solubility diagram with $\mathrm{HP} \beta-\mathrm{CD}$ at $25^{\circ} \mathrm{C}$ was compared with 
Higuchi and Connors standard graph. ${ }^{14}$ In comparison, it was found that solubility of AZM increased with the concentration of HP $\beta$-CD linearly. Hence it was AL-type ${ }^{18}$ diagrams which suggested 1:1 molar ratio (Figure 1). From the phase solubility studies, it was concluded that inclusion complex phenomena for AZM are perfect with HP $\beta$-CD. HP $\beta$-CD has more ability to improve solubility compared to $\beta$-CD. Stability constants, (Kc) was found to be $8.33 \times 10^{4} \pm 1.56 \times 10^{4}$ (Table 1 ).

The Gibbs free energy $\left(\Delta \mathrm{G}^{\circ}\right)$ of Azithromycin from the aqueous solution to the cavity of the HP $\beta$-CD could be calculated using the following equation. ${ }^{23}$

$$
\Delta \mathrm{G}^{\mathrm{o}}=-2.303 \times \mathrm{R} \times \mathrm{T} \times \log \mathrm{S}_{0} / \mathrm{S}_{\mathrm{S}} .
$$

The negative values of $\Delta \mathrm{G} \pm 25^{\circ} \mathrm{C}$ were found for AZM in Table 2, show that intermolecular interaction for AZM was spontaneous processes.

\section{Van't Hoff plot}

The integrated form of the Van't Hoff equation enables the calculation of the enthalpy $(\Delta \mathrm{H})$ and of entropy changes $(\Delta \mathrm{S})$, depending on the variations of the stability constants with temperature. ${ }^{24}$

$$
\begin{aligned}
& \ln K_{\mathrm{c}}=-\frac{\Delta H^{\mp}}{R T}+\frac{\Delta S^{\mp}}{R} . \\
& \Delta \mathrm{H}=-\mathrm{R} \times \text { Slope } \\
& \Delta \mathrm{S}=\mathrm{R} \times \text { Intercept }
\end{aligned}
$$

The Van't Hoff plots for the inclusion complexed AZM- HP $\beta$-CD inclusion complexed show a linear behaviour, as reported in Figure 2. The positive values of enthalpy changes $\left(10.56 \mathrm{kJmol}^{-1}\right)$ indicate that the dissolution process of AZM (dehydration of guest molecule) in is endothermic.

The changes of entropy $\left(-11.84 \mathrm{Jmol}^{-1} \mathrm{~K}^{-1}\right)$ was found to be negative. It explained that complexation causes a decrease in translational and rotational degrees of freedom of the complexed molecule as compared with the free ones, giving a more ordered system. These results indicate that the complexation of AZM with HP $\beta$-CD has occurred.

\section{Stoichiometry Determination: Job's plot (continuous variation Method)}

The stoichiometry of complex formation between AZM and the HP $\beta$ CD was 1: 1 which was again confirmed by Job's method. In Figure 3, the maxima peak was obtained at 0.5 , which again suggested the ratio of $1: 1$ for AZM and HP- $\beta$-CD for inclusion complexes.

\section{Solubility studies}

The solubility of Azithromycin in distilled water was found to be $0.175 \pm$ $0.015 \mu \mathrm{g} / \mathrm{ml}$ at room temperature. The complex formation of AZM with $\mathrm{HP} \beta-\mathrm{CD}$ resulted in more than nine-fold $(0.996 \pm 4.2 \mu \mathrm{g} / \mathrm{ml})$ increase in solubility in Table 3.

\section{Dissolution studies}

The dissolution profiles of the inclusion complexes compared with pure AZM and its physical mixture are shown in Figure 4. As dissolution profiles, the inclusion complex showed much high dissolution rate than the compare to physical mixture and pure AZM, with a cumulative drug release $82.78 \%$ within 120 min (kneading method), $71.55 \%$ within 120 min (solvent evaporation). Besides that, free AZM exhibited a low dissolution rate about $30 \%$ and $42 \%$ at 60 and 120 min respectively. These facts supported the results of phase solubility studies and further supported the fact of conversion of Azithromycin to an amorphous form of inclusion complex due to increasing wettability. Hence it enhanced the drug release rate. Hence, dissolution study of the physical mixture also exhibited a small improvement due to the presence of $\mathrm{HP} \beta-\mathrm{CD}$ and showed a dissolution amount of $33 \%$ at $60 \mathrm{~min}$ but was almost equal to the pure AZM at $120 \mathrm{~min}$ because no any type of interaction was observed. Therefore it concluded that the AZM/HP $\beta-C D$ inclusion complex showed faster dissolution compare to the pure AZM drug.

\section{Solid state characterization of inclusion complex}

\section{Fourier transform infrared spectroscopic analysis}

FTIR is a useful technique to prove the presence of intermolecular interaction in their inclusion complexes. Figure 5 shows the FTIR spectrum for the (a) HP $\beta$-CD (b) AZM (c) Inclusion complex of AZM/HP $\beta-C D$. The IR spectrum of pure AZM [Figure 7a] was characterized by prominent peaks $3561.84 \mathrm{~N}-\mathrm{H}$, stretch secondary amine $3490.7 \mathrm{OH}$ group, 2937.1C-H stretch aliphatic, 2780.2 C-H stretching vibration, 1720.2 $\mathrm{C}=\mathrm{O}$ stretchings (Ketone), 1451.8 C-N stretchings (amines), 1377.37 $\mathrm{C}-\mathrm{H}$ deformations in alkane, $1241.23 \mathrm{C}-\mathrm{O}-\mathrm{C}$ ether stretching, 1082.8 Aliphatic C-O stretching, 1049.28 OH bending (alcohol), 796.60 Skeletal vibrations of aromatic ring (820-690), 731.02 Mono substituted aromatic ring, $640.37 \mathrm{C}-\mathrm{H}$ deformation. The IR spectrum of HP $\beta$-CD [Figure b] was characterized by prominent peaks at $3319 \mathrm{~cm}^{-1}(\mathrm{O}-\mathrm{H}), 2927.8$ $\mathrm{cm}^{-1}(\mathrm{C}-\mathrm{H}), 1638.2 \mathrm{~cm}^{-1}$ (H-O-H bending), $1079.1 \mathrm{~cm}^{-1}$ (C-O-C). In case of inclusion complex, few peaks in the spectra of AZM were slightly shifted and few peaks were found to be reduced. Besides that, a broadening of hydroxyl band of HP $\beta-C D$ at $3363.9 \mathrm{~cm}^{-1}$ was observed to be narrowed in the FTIR spectrum of the AZM/HP $\beta$-CD inclusion complex which indicated the formation of the inclusion complex. This type of broadening situation was noticed by many scientists for making the inclusion complex between host-guest molecules. In addition, the peak of $-\mathrm{N}$ - stretch was not visible might be overlapping with $\mathrm{O}-\mathrm{H}$ stretch of $\mathrm{HP} \beta-\mathrm{CD}$. It concluded that significant changes were observed in the

Table 1: Stability of constant values for the complex formation of azithromycin with HP- $\beta C D$ at various temperature.

\begin{tabular}{cc}
\hline Temperature(K) & $\mathrm{Kc}^{\left(\mathrm{M}^{-1}\right)}$ \\
\hline 298.15 & $8.33 \times 10^{4} \pm 1.56 \times 10^{4}$ \\
300.15 & $5.78 \times 10^{4} \pm 0.63 \times 10^{4}$ \\
306.15 & $4.82 \times 10^{4} \pm 0.3 \times 10^{4}$ \\
320.15 & $3.60 \times 10^{4} \pm 0.2 \times 10^{4}$ \\
\hline
\end{tabular}

Table 2: Gibbs free energy of transfer $(\Delta G)$ for the solubilization process of $A Z M$ in an aqueous solution of $H P-B C D$ at $25^{\circ} \mathrm{C}$.

\begin{tabular}{cc|}
\hline Concentration of HP- $\beta C D(\mathrm{mM} / \mathrm{L})$ & $\begin{array}{c}\Delta \mathrm{G} \\
\left(\mathrm{Jmol}^{-1}\right)\end{array}$ \\
\hline 3 & $-1627.14 \pm-325$ \\
6 & $-3820.36 \pm-230$ \\
9 & $-5178.95 \pm-630$ \\
12 & $-6122.50 \pm-230$ \\
\hline
\end{tabular}

Table 3: Solubility study of Azithromycin dehydrate in Physical mixture and inclusion complex.

\begin{tabular}{cc}
\hline & Solubility $(\mu \mathrm{g} / \mathrm{ml})$ \\
\hline Drug (pure) & $1.75 \pm 0.015$ \\
Physical mixture & $2.25 \pm 0.036$ \\
Kneading method & $9.96 \pm 0.05$ \\
Solvent evaporation & $6.52 \pm 0.05$ \\
\hline
\end{tabular}



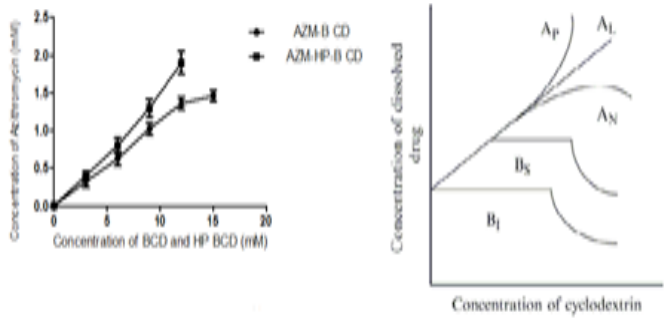

Figure 1: Stability of constant values for the complex formation of azithromycin with $\mathrm{HP}-\beta \mathrm{CD}$ at various temperature.

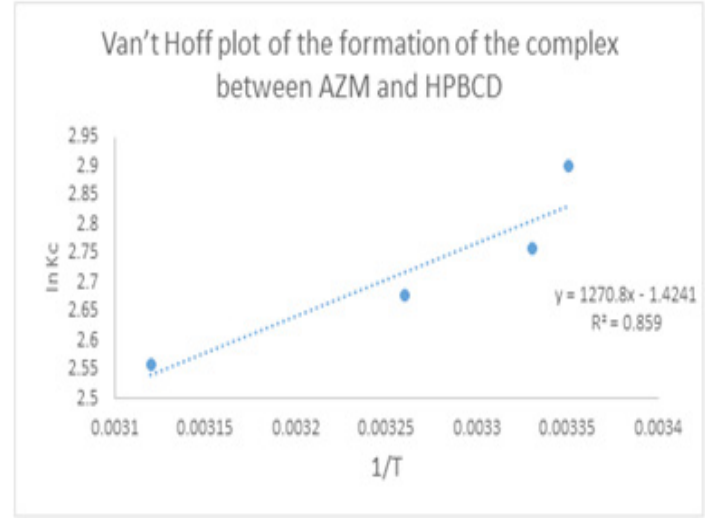

Figure 2: Van't Hoff plot for inclusion complex AZM/ HP- $\beta C D$.

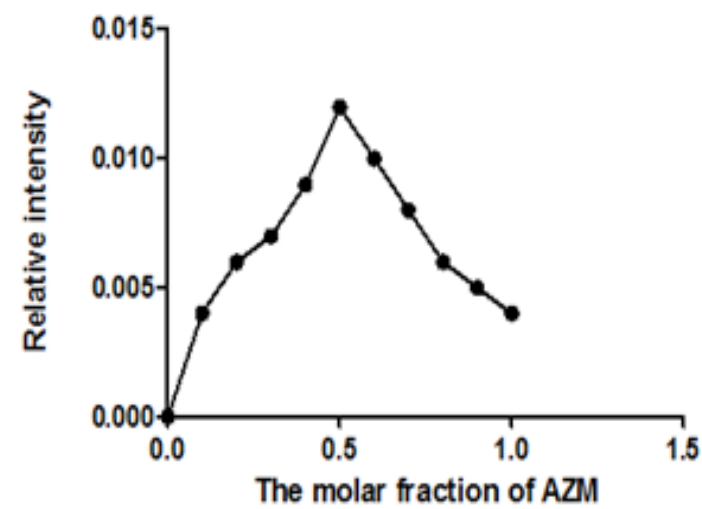

Figure 3: Job's plot for AZM/HPß-CD complex.

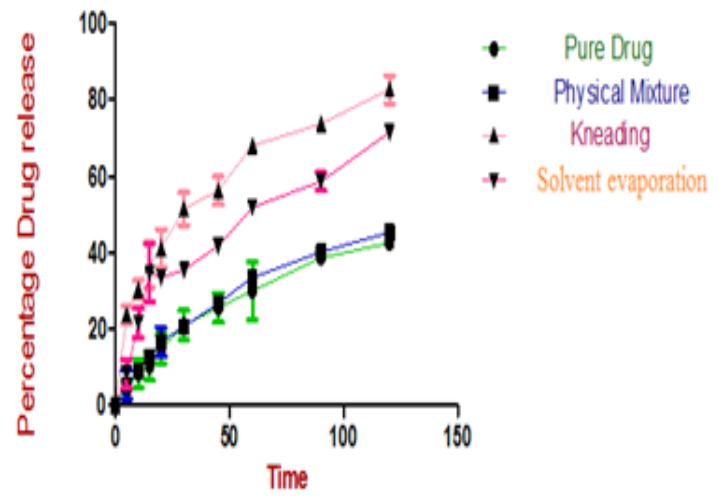

Figure 4: Comparison of dissolution study of AZM in the physical mixture, kneading and solvent evaporation.
IR spectra of the inclusion complex prepared by the kneading suggested intermolecular interaction.

\section{Differential scanning calorimetry analysis}

Figure 6 shows the thermograms of AZM, HP $\beta$-CD and the AZM/HP $\beta$ $\mathrm{CD}$ inclusion complexes prepared from kneading method. Thermogram of AZM exhibited one endothermic peak at $124.37^{\circ} \mathrm{C}$, whereas $\mathrm{HP} \beta-\mathrm{CD}$ showed a peak at $73.55^{\circ} \mathrm{C}$. The thermograms of AZM/HP $\beta-\mathrm{CD}$ inclusion complex showed only one endothermic peak for the inclusion complex. It was noted that the characteristic endothermic peak of AZM was disappeared. It suggested AZM hydrophobic molecule (guest molecule) inclusion into the cavity of $\mathrm{HP} \beta-\mathrm{CD}$ (host molecule) has been occurred, indicating the formation of the inclusion complex.

\section{${ }^{1} H$ NMR analysis}

Figure 7 presents the ${ }^{1} \mathrm{H}-\mathrm{NMR}$ spectra of $\mathrm{HP} \beta-\mathrm{CD}$, AZM and AZM/ $\mathrm{HP} \beta-\mathrm{CD}$ inclusion complex respectively in DMSO. The main chemical shifts at 1.07, 1.26, $10.02 \mathrm{ppm}$ in Figure $6 \mathrm{~b}$ represented to $\mathrm{a}, \mathrm{b}$ and $\mathrm{c}$ respectively in the AZM spectra. In comparision of chemical shifts of AZM with AZM/HP $\beta-C D$ inclusion complex, several changes were noted. For AZM, the Ha and Hc shift were changed. Hb shift was not visible in the $1 \mathrm{H}-\mathrm{NMR}$ spectra of AZM/HP- $\beta$-CD complex. Hence it was confirmed that intermolecular interaction has occurred between AZM and HP $\beta$ CD.
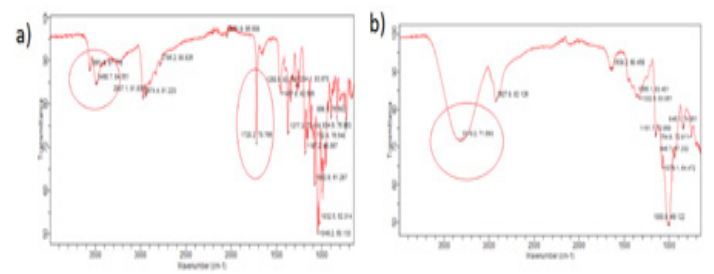

c)

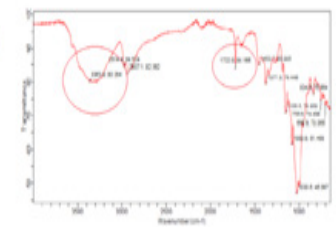

Figure 5: FTIR spectrum for the (a) HPß-CD (b) AZM (c) inclusion complex of $A Z M / H P \beta-C D$.

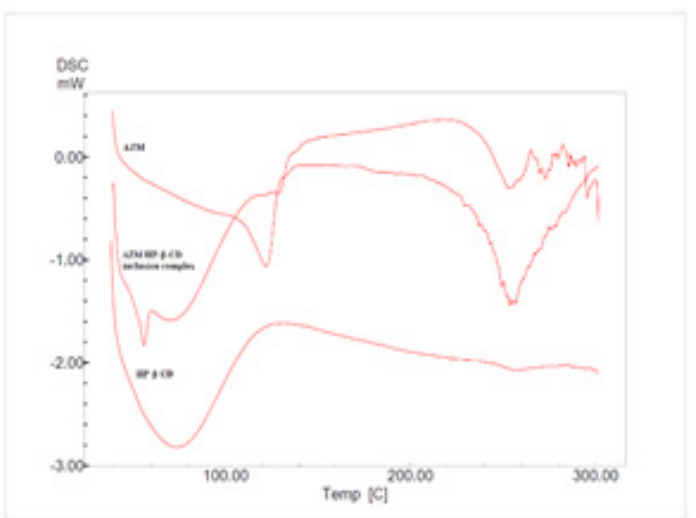

Figure 6: Thermograms of $A Z M, H P \beta-C D$, the $A Z M / H P \beta-C D$ physical mixture and the inclusion complex. 


\section{Scanning electron microscopy studies}

SEM photomicrographs of AZM, HP $\beta-C D$ and AZM/HP $\beta-C D$ inclusion complex are reported in Figure 8. It was observed that AZM in regularly shaped crystals while $\mathrm{HP} \beta-\mathrm{CD}$ in amorphous hollow spherical particles. But on the case of Inclusion complex, it was noted that AZM molecules agglomerated on the surface of $\mathrm{HP} \beta-\mathrm{CD}$ particles. It was noted that AZM molecule agglomerated on the surface of HP $\beta$-CD. This suggested the formation of a new solid state due to crystalline habitus change. It supported the facts of the presence of a single solid state. This result suggested a close association between $A Z M$ and $H P-\beta C D$. It also supported the fact that AZM no longer existed in the crystal state. From SEM studies confirmed the inclusion complexes formation by the inclusion of AZM inside HP- $\beta$ CD.

\section{Stability study}

From the stability study of the AZM/HP $\beta-C D, A Z M$ powder and its physical mixture at $40 \pm 1^{\circ} \mathrm{C}, 75 \pm 5 \% \mathrm{RH}$, the results are shown in Figure 9. The amount of AZM in pure powder and the physical mixture gradually decreased with time. But the AZM/HP $\beta-C D$ inclusion complexes was delayed the reduction of AZM contents. There was no significant change was observed in the stability study of AZM/HP $\beta-C D$ inclusion complexes over the three months.

\section{DISCUSSION}

Azithromycin (AZM) was entrapped into hydroxypropyl- $\beta$-cyclodextrin achieving the improvement of its biopharmaceutical properties of low solubility. Phase solubility was performed with use $\beta$-cyclodextrin and hydroxypropyl- $\beta$-cyclodextrin using Higuchi and Connors method. AN-type phase-solubility curve was found with $\beta$-cyclodextrin. ${ }^{14}$ The high molecular weighted AZM has difficult to accommodate into smaller cavity size of $\beta$-CD. In addition, the graph showed a negative deviation

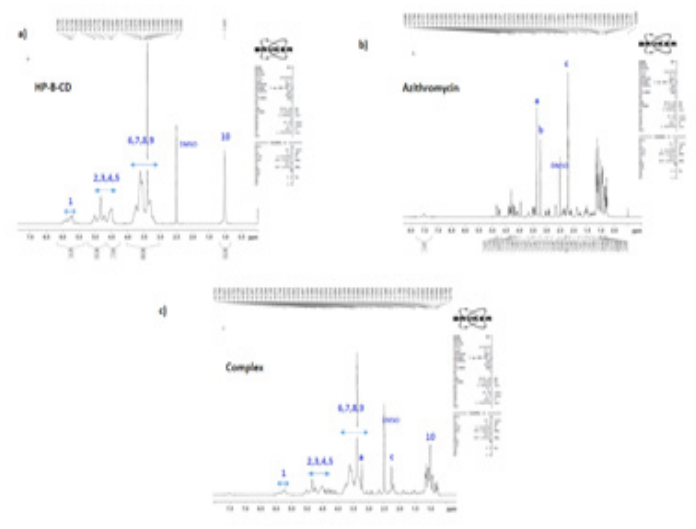

Figure 7: ${ }^{1} \mathrm{H}-\mathrm{NMR}$ spectra of $\mathrm{HP} \beta-\mathrm{CD}, \mathrm{AZM}$ and the $\mathrm{AZM} / \mathrm{HP} \beta-\mathrm{CD}$ inclusion complex.
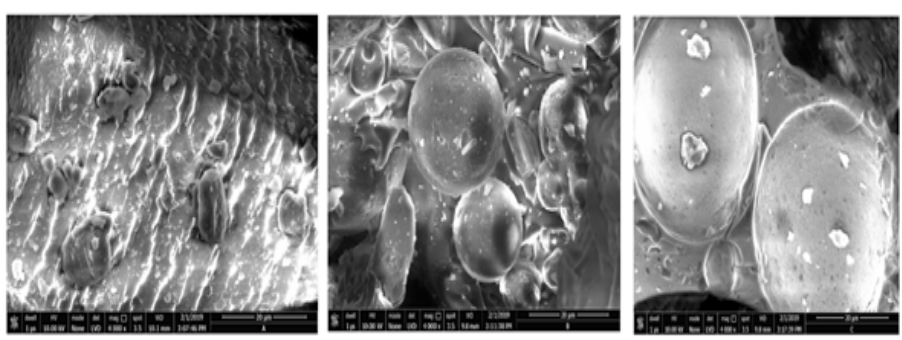

Figure 8: SEM photomicrographs of $A Z M, H P \beta-C D$ and $A Z M / H P \beta-C D$ inclusion systems.

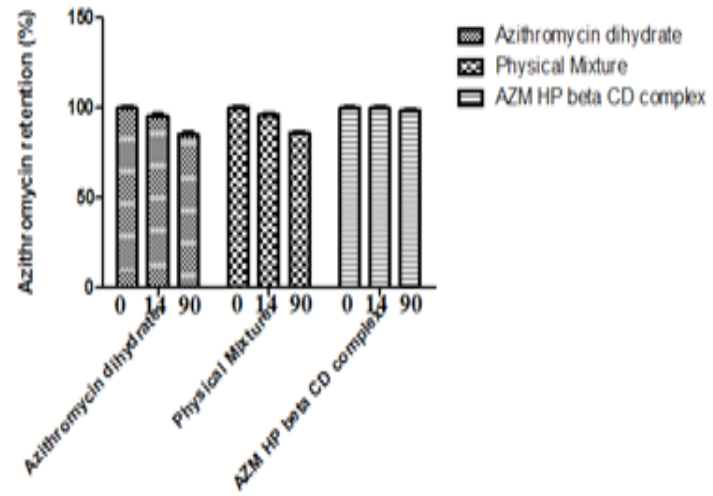

Figure 9: Stability study.

from linearity which indicated variation in dielectric constant, complex solubility process or self-association process of cyclodextrin by host molecules. Second host-guest stoichiometry for Azithromycin (AZM)/ hydroxypropyl- $\beta$-cyclodextrin was found to AL-type ${ }^{14}$ which indicated improvement in solubility which also confirmed by Job Plot. ${ }^{16}$ It can be observed that the values of the stability constants, Kc, decrease as the temperature increase which indicates the temperature have effect on stability of the inclusion complexes and also indicated an endothermic and spontaneous process. Temperature had an effect on the stability of the inclusion complexes which indicated an endothermic and spontaneous process. The negative values of $\Delta \mathrm{G}^{23} \pm 25^{\circ} \mathrm{C}$ was pointed intermolecular interaction for AZM was spontaneous processes. The Van't Hoff plots for the AZM/HP $\beta-C D$ inclusion complex showed a linear behaviour. The Value of Enthalpy and entropy obtained from Van't Hoff plots indicated that hydrophobic interaction was responsible for formation of inclusion complex. ${ }^{24}$ The inclusion complex Azithromycin (AZM)/ hydroxypropyl$\beta$-cyclodextrin were prepared by two methods like solvent evaporation method ${ }^{18}$ and kneading method. ${ }^{17}$ This high improvement in the solubility was found for the inclusion complex prepared by kneading method. The inclusion complex formation of AZM with HP $\beta$-CD resulted in more than nine-fold $(0.996 \pm 4.2 \mu \mathrm{g} / \mathrm{ml})$ increase in solubility (in kneading method). As dissolution profiles, inclusion complex with kneading method has high dissolution rate as compare to inclusion complex with solvent evaporation, pure AZM and physical mixture. Kneading method was best to enhance solubility and dissolution of AZM by using inclusion complex compare to pure drug, physical mixture and solvent evoparation. It indicated improvement in solubility and conversion of crystalline Azithromycin to an amorphous form of inclusion complex due to increasing wettability. In addition, $\mathrm{HP} \beta-\mathrm{CD}$ reduced the interfacial surface tension between drug molecules and the dissolution medium due to its surfactant nature. The AZM/HP $\beta-C D$ inclusion complex showed faster dissolution compare to the pure AZM.

The inclusion complex AZM/ hydroxypropyl- $\beta$-cyclodextrin was again confirmed by FT-IT, DSC, HNMR, SEM. The significant changes were observed in the FT-IR spectra of the inclusion complex prepared by the kneading suggested intermolecular interaction. The DSC thermograms of AZM/HP $\beta$-CD inclusion complex showed only one endothermic peak for the inclusion complex and also characteristic endothermic peak of AZM was disappeared. Various chemical shift was observed in HNMR. SEM study suggested the formation of a new solid state due to crystalline habitus change. This solid state characterization study revealed about intermolecular interaction between AZM and hydroxypropyl- $\beta$ cyclodextrin. It suggested AZM hydrophobic molecule (guest molecule) inclusion into the cavity of $\mathrm{HP} \beta-\mathrm{CD}$ (host molecule) has been occurred. It also indicated that amorphous nature of inclusion complex. AZM/ 
HP $\beta$-CD inclusion complex was found to be stable over three months during stability study.

\section{CONCLUSION}

In the study, the phase solubility, dissolution behavior and solid-state characterization of AZM/HP $\beta$-CD inclusion complex were investigated. From phase Solubility studies, it was concluded that HP $\beta$-CD has more ability to improve solubility compared to $\beta$-CD. The Inclusion complex of $\mathrm{AZM} / \mathrm{HP} \beta-\mathrm{CD}$ was prepared by kneading and solvent evaporation in 1:1 ratio. Improvement in solubility and drug release rate were more in the kneading method compare to the physical mixture and solvent evaporation. The inclusion AZM/HP $\beta-C D$ was further confirmed by FTIR, DSC, HNMR and SEM study. From the solid state characterization, it was concluded that guest-hydrophobic molecules inclusion in host hydrophobic HP $\beta$-CD.

\section{CONFLICT OF INTEREST}

The authors confirm that this article content has no conflict of interest.

\section{ABBREVIATIONS}

AZM: Azithroycin dihydarte; HP $\boldsymbol{\beta}$-CD: Hydroxypropyl-beta-cyclodextrin; SEM: Scanning electron microscopy studies; DSC: Differential scanning calorimetry; FTIR: Fourier transform infrared spectroscopic analysis.

\section{REFERENCES}

1. Mohanty S, Mohapatra R, Patra S, Sahoo DK. Formulation and in-vitro evaluation of azithromycin mouth dissolving tablets using superdisintegrants. Res J Pharm Biol Chem. 2013;4(3):452-61.

2. Han MK, Tayob N, Murray S, Dransfield MT, Washko G, Scanlon PD. Predictors of chronic obstructive pulmonary disease exacerbation reduction in response to daily azithromycin therapy. Am J Respir Crit Care. 2014;189(12):1503-8.

3. Catherinot $E$, Roux $A$, Vibet $M$, Bellis G, Lemonnier L, LeRoux E. Inhaled therapies, azithromycin and Mycobacterium abscessus in cystic fibrosis patients. Eur Respir J. 2013;41(5):1101-6.

4. Kerc J, Mohar M, Srcic B, Smid KJ. Dissolution study of felodipine solid dispersions. Acta Pharm. 1993;43:113-20.

5. Popli H, Murthy RS, Miglani BD. Solid dispersions as a drug delivery system for sulphamethoxazole and nitrofurantoin. Ind J Hosp Pharm. 1997;31:97-100.

6. Connors KA. The stability of cyclodextrin complexes in solution. Chem Rev. 1997;97(5):1325-58

7. Szejtli J. Introduction and general overview of cyclodextrin chemistry. Chem
Rev.1998;98(5):1743-53.

8. Dalmora ME, Dalmora SL, Oliveira AG, Inclusion complex of piroxicam with beta-cyclodextrin and incorporation in cationic microemulsion: in vitro drug release and in vivo topical anti-inflammatory effect. Int J Pharm. 2001;222(1):4555.

9. Fermeglia M, Ferrone M, Lodi A, Pricl S. Host-guest inclusion complexes between anticancer drugs and b-cyclodextrin: Computational studies. Carbohydr Polym. 2003:53(1):15-44.

10. Chen J, Ohnmacht CM, Hage DS. Characterization of drug interactions with soluble beta-cyclodextrin by high-performance affinity chromatography. J Chromatogr. 2004;1033(1):115-26.

11. Uekama K, Hirayama F, Irie T. Cyclodextrin drug carriers systems. Chem Rev. 1998;98(5):2045-76

12. Jug M, Becirevic LM. Multicomponent complexes of piroxicam with cyclodextrins and hydroxypropyl methylcellulose. Drug Dev Ind Pharm. 2004;30(10):105160.

13. Kong RX, Zhu ES, Meteleva AV, Dushkin WS. Physicochemical characteristics of the complexes of simvastatin and atorvastatin calcium with hydroxypropylßcyclodextrin produced by mechanochemical activation. J Drug Deliv Sci and Technol. 2018;17:31132-10.

14. Higuchi T, Connors KA. Phase solubility Techniuqe. Adv Anal Chem Instrum. 1965;4:117-212.

15. Cristina S, María PB, María FM. Phase solubility studies of terpineol with betacyclodextrins and stability of the freeze-dried inclusion complex. J Sci Food Agric. 2014;153:361-70.

16. Shujing L, Yuan L, Yong C, Wei Z, Xinrui W. Studies on the Inclusion Complexes of Daidzein with $\beta$-Cyclodextrin and Derivatives. Molecules. 2017;22(12):1-11.

17. Anshu S, Jain CP. Carvedilol- $\beta$-cyclodextrin Systems: Preparation, Characterization and in vitro Evaluation. J Pharm Sci. 2013;12(1):51-8.

18. Rajesh NK, Bhanudas SK. Preparation, physicochemical characterization, dissolution and formulation studies of telmisartan cyclodextrin inclusion complexes. Asian J Pharm. 2010;4(1):52-9.

19. Lakshmi S, Mervin A, Jayashnkar L, Ramu P, Raja TK. Visible spectrophotometric methods for determination of Azithromycin in tablets. Indian J Pharm Sci. 2004;66(2):249-51.

20. Fangfang $X$, Qiuxia $Y$, Lilan W, Rui Q, Yunshan W, Yucui L, et al. Investigation of Inclusion Complex of Patchouli Alcohol with $\beta$-Cyclodextrin. Plos One. 2017;12(1):1-10

21. Chutima J, Pornpak S, Shantika R, Pawut W, Siripa S, Adil W, et al. CurcuminHydroxypropyl- $\beta$-Cyclodextrin Inclusion Complex Preparation Methods: Effect of Common Solvent Evaporation, Freeze Drying and pH Shift on Solubility and Stability of Curcumin. Trop J Pharm Res. 2014;13(8):1215-23.

22. ICH Q1A (R2). Stability testing guideline: Stability testing of new drug substance and products. ICH Steering Committee. 2003;4:1-24.

23. Rajesh NK, Bhanudas SK, et al. Preparation, physicochemical characterization, dissolution and formulation studies of telmisartancyclodextrin inclusion complexes. Asian J Pharm. 2010;4(1):52-9.

24. Zheng, Dong LN, Liu M, Chen AJ, Feng SC, Wang BO, et al. Effect of pH on the complexation of kaempferol-4-glucoside with three $\beta$-cyclodextrin derivatives: Isothermal titration calorimetry and spectroscopy study. J AgricFood Chem. 2014;62(1): 244-50.

Cite this article: Raval M, Bagada H. Preparation, Solid-State Characterization, Phase Solubility and Dissolution Studies of Azithromycin/Hydroxypropyl- $\beta-$ Cyclodextrin Host-Guest System. Int. J. Pharm. Investigation. 2019;9(4):174-9. 